\title{
DIREITOS HUMANOS E A NECESSIDADE DE UMA GESTÃO EDUCACIONAL MEDIADORA NA SOCIEDADE CONTEMPORÂNEA
}

\section{HUMAN RIGHTS EDUCATION AND THE NEED FOR AN EDUCATIONAL MANAGEMENT MEDIATOR ON THE CONTEMPORARY SOCIETY}

\author{
Maria Gorete Ferreira \\ mgfunivas@hotmail.com
}

Rosa Maria Nascimento

pesquisa@univas.edu.br

Recebido: 29/08/2013

Aprovado:07/11/2013

SUMÁRIO: 1. Introdução. 2. Direitos Humanos e suas violações em relação à educação. 3. Democracia e as garantias constitucionais para assegurar os direitos sociais: educação. 4. Gestão Escolar como paradigma para a organização e desenvolvimento do sistema Escolar. 5. A gestão educacional como mediadora da educação em uma comunidade. 6. Considerações Finais. 7. Referências

\section{Resumo:}

O presente artigo ressalta a importância dos direitos humanos em educação e a necessidade de uma gestão educacional mediadora da cultura social da diversidade, bem como a influência que uma comunidade pode ter na sociedade contemporânea, quando é conhecedora dos direitos humanos essenciais à dignidade humana. O texto discute a relevância do papel desempenhado pela gestão educacional como mediadora junto à escola e à comunidade, as quais buscam uma democracia, por meio das garantias constitucionais e efetivação dos direitos sociais, especialmente, o direito à educação, que possui

\section{Abstract:}

The present article emphasizes the importance of human rights education and the need for an educational management mediator between diversity's social culture, as well as communities' influence on the contemporary society - the kind of society which recognizes those rights essential to human dignity. The text discusses educational management actions and their relevance by mediating the reality between schools and communities which seek democracy through constitutional "guarantees" and social rights effectuation, especially the right to education that can transform the individual 
um caráter transformador do indivíduo como membro social de uma comunidade. A gestão educacional funciona como um instrumento direcionador do trabalho organizacional e estrutural da escola, porém, isso só se efetiva se houver interação da comunidade, em situações de desafios no desenvolvimento do trabalho do gestor escolar e suas práticas metodológicas, com vistas a ampliar o conhecimento, a amplitude, e, principalmente, a oportunidade de participação do cidadão em qualquer dos setores da sociedade. Isso somente será possível com a instrução educacional mais elevada e com uma maior difusão, compreensão e efetivação dos direitos humanos.

\section{Palavras-Chave:}

Direitos Humanos. Educação. Gestão Educacional. Sociedade into a social member of a community. This management works as a guide capable to lead the school, as an institution, to another level in therms of organization and structure. However, this is only possible with communities' interaction in challenging situations of the educational manager's work development and its methodological practices in order to widen knowledge and opportunities that allow the citizen to participate of any society's area.

\section{Keywords:}

Human Rights. Education. Education Management. Contemporary society.

\section{Introdução}

O presente artigo tem por finalidade vislumbrar a importância e a necessidade extrema de uma gestão educacional que busque contemplar os objetivos fundamentais da República Federativa do Brasil, quais sejam: construir uma sociedade livre, justa e solidária; garantir o desenvolvimento nacional; erradicar a pobreza e a marginalização e reduzir as desigualdades sociais e regionais; promover o bem de todos, sem preconceitos de origem, raça, sexo, cor, idade e quaisquer outras formas de discriminação (BRASIL, 1988).

É de fundamental importância que a sociedade brasileira contemporânea tenha em vista a relevância de implementações de políticas públicas e inovação, em gestão educacional de qualidade para que possamos atingir a falha que há em nosso sistema educacional. $\mathrm{E}$ com isso, podendo-se atingir os objetivos fundamentais, para se obter uma sociedade que promova o bem estar de todos assegurados na Constituição da República e na Declaração Universal dos Direitos Humanos ${ }^{1}$.
1. A presente Declaração Universal dos Diretos Humanos como o ideal comum a ser atingido por todos os povos e todas as nações, com o objetivo de que cada individuo e cada órgão da sociedade, tendo sempre em mente esta Declaração, se esforce, através do ensino e da educação, por promover o respeito a esses direitos e liberdades, e, pela adoção de medidas progressivas de caráter nacional e internacional, por assegurar o seu reconhecimento e a sua observância universais e efetivos, tanto entre os povos dos próprios EstadosMembros, quanto entre os povos dos territórios sob sua jurisdição. ORGANIZAÇÃO DAS NAÇÕES UNIDAS (ONU). Resolução 217. A de 10 de dezembro de 1948. 
Os elementos da gestão educacional funcionam como base organizacional da estrutura e administração da escola. Assim, para que haja gerência eficiente numa instituição de ensino é necessário o movimento entre a sociedade e suas condições de realidade social.

É inquestionável a ideia de que o acesso à educação é um direito fundamental inerente a todo cidadão, mas a fruição efetiva de tal direito se contrapõe ao reconhecimento das lideranças políticas, mesmo sendo este uma garantia constitucional, em que a efetividade dos direitos sociais depende de ações estatais concretas, visto que sua plena satisfação extrapola o nível da satisfação individual do direito (DUARTE, 2004).

A Constituição da República traz em seu artigo 205 que: “ $A$ educação, direito de todos e dever do Estado e da família, será promovida e incentivada com a colaboração da sociedade, visando ao pleno desenvolvimento da pessoa, seu preparo para o exercício da cidadania e sua qualificação para o trabalho" e como atividade do Estado torna-se instrumento de concretização do programa constitucional, já que esse acesso às políticas educacionais, direito de cada cidadão (BRASIL, 1988).

A educação em sua amplitude tem a finalidade de tornar o homem mais integro, fornecendo-lhes meios de aplicabilidade do conhecimento adquirido de forma disciplinada através de instrução educacional, o que, embora possa ser entendida como linhas paralelas, instrução e educação devem se completar, ou mesmo, integrar-se (MUNIZ, 2002).

Vale destacar que o primeiro documento de cunho internacional a tratar sobre o assunto foi a Declaração Internacional dos Direitos Humanos de 1948, que recebeu complemento direto e posterior pelo Pacto sobre os Direitos Civis e Políticos e Direitos Econômicos, Sociais e Culturais adotados pela Assembleia Geral das Nações Unidas datada de 1966 (ALVES, 1997).

Uma educação de acordo com os direitos humanos exige uma estrutura e, principalmente, uma conscientização por parte da sociedade, no que se refere à aplicação de políticas públicas. O contexto vivenciado pela sociedade, sem dúvida, acaba refletindo na escola e nos seus pilares. Sabe-se que há uma distância entre os valores que a escola é capaz de transmitir ao cidadão e o conhecimento sobre a importância do acesso e a permanência nela. Esse distanciamento gera fragmentação nos projetos de políticas públicas, tornando-as ineficientes e ineficazes. Dessa forma, é primordial que a sociedade contemporânea estabeleça relações entre educação e democracia, e reconheça as dimensões públicas 
e socializadoras que, historicamente, foram sendo construídas pelas camadas populares, na convicção de que não haverá democracia social sem a compreensão e a participação social.

No entanto, para pontuar melhor compreensão dos conceitos e das relações entre democracia, educação, necessidade de gestão educacional e direitos humanos, neste artigo, faz-se uma discussão referente às temáticas democracias, gestão educacional e gestão democrática de modo a configurar os pressupostos constitucionais que orientam o presente trabalho.

Os autores Fávero e Semeraro (2002) confirmam essa ideia ao destacar que: ao lado de outras forças sócio-políticas-culturais que vêm transformando o Brasil, a luta por uma escola pública, universal e de qualidade empreendida pelos educadores brasileiros representa a expressão peculiar e inseparável da educação, ao mesmo tempo que se torna poderosa contribuição para o processo de democratização do país.

Partindo desses pressupostos, verifica-se que a educação, ao ajustar-se à promoção social e intelectual das diversas esferas multiculturais de que se compõe nossa sociedade, resiste à submissão realizada por projetos impostos de fora e de cima, que não se permitem instrumentalizar pelo mercado. A educação faz-se portadora de uma concepção de democracia que institui sujeitos políticos ativos e capazes de responsabilidades sociais, de reinventar o mundo e de recriar um Estado realmente público.

Por outro lado, destaca-se que a investigação constitui um desvelamento dos desafios e das limitações da gestão na condução e na promoção do processo dialógico acerca dos direitos humanos num contexto social marcado pelo preconceito, pela exclusão, pela desigualdade social e por muitas resistências em relação à educação em direitos humanos.

A educação em direitos humanos implica a transformação de uma cultura que tradicionalmente vem marcada pelo preconceito e pelo desrespeito aos direitos humanos. Nessa expectativa demonstrase uma ponderação sobre a importância da escola contemporânea, como instituição mediadora e transformadora das relações sociais da comunidade, por meio da interação de conflitos e situações específicas da educação. 


\section{Direitos Humanos e suas violações em relação à educação}

A questão do atendimento aos direitos humanos no interior da escola, ou seja, na realidade da educação, partindo dos princípios do Plano Nacional de Educação em Direitos Humanos (PNEDH), suas implicações para a prática gestora, para implementação de políticas públicas educacionais, tem evidenciado ser uma proposta que não conseguiu envolver os educadores que irão executá-la na escola, o que poderá comprometer o seu sucesso.

Para Gimeno Sacristan (1999), reforma pode ser compreendida como ação parcial ou programas para introduzir mudanças no sistema, como medidas da política educacional. A expressão direitos humanos é recorrente, porém, pouco se discute o que são, quais são, como atendêlos, o que implicam e a relação direitos e deveres. Seu uso, aliado ao crescente apelo para o reconhecimento de novos direitos, banaliza e esvazia seu significado, dificultando a percepção de que leis, políticas e planos são necessários, mas insuficientes para garantir seu atendimento.

O PNEDH necessita de ações políticas complementares para sua implantação, estando sujeito à interferência, à cultura, à ideologia e à vivência de seus executores. Educadores comprometidos podem experimentar a sensação de que já trabalham nesse sentido. Contudo, será que o fazem adequadamente? Gimeno Sacristan questiona: tem-se

2. 1. Entendimento através da palavra, conversação, colóquio, comunicação. 2. Discussão ou troca de ideias, conceitos, opiniões, objetivando a solução de problemas e a harmonia.

3. O diálogo e a participação na educação é mediação fundamental para viabilizar a mudança social na medida em que proporciona uma comunicação crítica da realidade e contribui para a formação de sujeitos autônomos, comprometidos com a prática social. WEYH, Cênio Back; DUARTE, Letícia Rieger. SILVA, Mariana Scholze da. Participação e diálogo no caminho da educação popular. Vivências. Vol.6, N.11: p.107111, Outubro/2010. direito à educação, mas estamos de acordo com as características gerais que se deve ter? (GIMENO SACRISTAN, 2007).

Ao gestor educacional de uma instituição de ensino numa comunidade cabe a motivação, a administração, a organização e a coordenação dos agentes e da escola para a execução do PNEDH. A partir de seus princípios, que visam à uma Educação Básica e de qualidade, com o intuito de desenvolver uma cultura de direitos humanos em todos os setores sociais.

A gestão educacional precisa demonstrar sua amplitude com relação ao contexto social que não se restringe à escola, o que exige preparar a criança para compreender direitos e deveres exigidos para uma convivência solidária, por meio de atividades internas e externas, exercitando a análise, o diálogo ${ }^{2}$ e a participação ${ }^{3}$. Dessa forma, os cidadãos terão oportunidade de conhecer direitos, deveres, responsabilidades e punições, possibilitando visão mais ampla sobre a percepção de atos que lesam os direitos humanos na escola e na sociedade. Apenas quando 
é vivenciada a democracia no interior da escola o educando adquire condições de aprender e exercê-la no contexto social.

A escola, como espaço privilegiado, opera como instrumento de construção e de consolidação da cultura de direitos humanos, pois deve assegurar que os objetivos e as práticas a serem adotadas sejam coerentes com os valores de ética e moral, pilares de qualquer meio para a transformação social.

Há que se compreender que, se a inclusão na escola é um dever, a negativa, mesmo quando justificada pela total ausência de vagas, expressa a subtração da escolaridade, condição insuficiente, porém primordial para o inicio do atendimento do direito humano da criança, adolescente, jovem ou adulto de educar-se. A entrada do aluno na escola mostra o início de um processo de atendimento a um direito humano, que terá continuidade se a escola empenhar-se no exercício de sua função formadora e informadora.

A gestão escolar deve atuar em face de conflitos, estimulando a discussão de ideias e não de pessoas. Deslocando-se o foco, assim poderá ampliar as ideias, enriquecer o trabalho, estabelecer consensos ${ }^{4}$ em torno do que é importante para fortalecer projetos coletivos que visam à uma melhoria na sociedade. Também é fundamental promover debate, uma linguagem na escola para o conhecimento e divulgação dos direitos humanos.

A educação em direitos humanos possui caráter coletivo, democrático e participativo e deve ocorrer em espaços marcados pelo entendimento mútuo, respeito e responsabilidade dos gestores no ambiente escolar. Em qualquer organização, sempre surgem conflitos, e em um ambiente voltado para uma educação coerente com os direitos humanos, estes não podem ser negados, mas enfrentados, para que sejam superados e para que haja o entendimento mútuo entre alunos, gestores e sociedade.

A sociedade é heterogênea e individualista. Nesse sentido, podese dizer que vigora a lógica do mercado capitalista e não as necessidades humanas. As crianças pobres, que mais precisam da escola, são as que menos têm poder e capacidade de fazer valer suas reivindicações ou de insistir para que suas necessidades sejam satisfeitas. (CONNELL, 1995).

A construção de uma escola com equidade e qualidade deve nortear a ação gestora. Apple lembra que não se pode desvincular a ênfase na organização de grupos heterogêneos, defendida por tantos grupos contemporâneos, da luta mais longa do movimento pelos
4. Consenso não é um sistema de votação, mas uma forma que todo o grupo ou comunidade entra na tomada de decisão. "0 consenso leva em conta preocupações de todos e visa a resolvê-los/ aclará-los antes que a decisão seja tomada. 0 mais importante, neste processo é incentivar um ambiente em que todos são respeitados e todas as contribuições são avaliadas. 0 consenso formal é um processo de decisão mais democrático. Grupos que desejam envolver sempre mais voluntários na participação têm a necessidade de utilizar um processo inclusivo. Para atrair e envolver cada vez mais pessoas é importante que o processo incentive a participação, permita o acesso igual ao poder, desenvolva a cooperação e crie um sentido da responsabilidade individual para as ações do grupo. 0 objetivo do consenso não é a seleção de diversas opções, mas o desenvolvimento de uma decisão que seja a meIhor para o grupo como um todo. É em síntese evolução, não competição nem atrito." CONTEÚDO aberto. In: Wikipédia: a enciclopédia livre. Disponivel em: http://a-enciclopedia-livre.info/?title =Consenso. Acesso em: 8 jul 2013. 
direitos civis (APPLE, 2001). Buscar a homogeneidade é afronta aos direitos humanos, já que somos todos diferentes. Mais do que adaptar o currículo às diferenças individuais, é preciso combater as desigualdades (GIMENO SACRISTAN, 1998).

Dessa forma, as ações e programas voltados para os problemas relacionados à educação não têm consistência, ou seja, acabam sendo banalizados e esvazia-se seu real significado, dificultando, assim, a percepção de leis, políticas e planos necessários, mas insuficientes para garantir a aplicação e o atendimento dos direitos humanos.

De outro lado, estamos vivendo num tempo e num espaço marcados por grandes, rápidas e avançadas transformações no campo tecnológico que, por mais paradoxal que pareça, não conseguem reverter a grande desigualdade social e a violação de direitos em que estamos imersos. É impossível contabilizar em números a quantidade de pessoas mortas pela escravidão, pela crueldade da colonização feita por extermínio de etnias, por atos de violação, por intolerância ideológica, étnica, racial, sexual e religiosa. Existem homens, mulheres e crianças que continuam não podendo exercer seus direitos fundamentais: o direito a vida, ou ainda, o princípio da dignidade humana, que contempla o princípio matriz do constitucionalismo contemporâneo. No entanto, a dignidade seria uma qualidade que, por ser inerente ao ser humano, o distinguiria dos demais.

Para melhor compreensão dessa dogmática, centramo-nos em Bobbio (2004). Para esse autor, os direitos humanos são o produto não da natureza, mas da civilização humana; enquanto direitos históricos são mutáveis, ou seja, suscetíveis de transformação e de ampliação. A dinâmica da sociedade vai criando novos direitos de acordo com o desenvolvimento e as transformações do contexto histórico e social de uma coletividade e das situações conflituosas existentes. Numa sociedade que se proclama democrática, os direitos, entre eles, à educação, são aqueles que, atendidos, possibilitam ao homem tornar-se cidadão, sujeito, capaz de participar de decisões que o afetam.

Em 1948, a Declaração Universal dos Direitos Humanos (Resolução 217 A - III, ONU) estabelece:

Artigo XXVI - Toda pessoa tem direito à instrução. A instrução será gratuita, pelo menos nos graus elementares e fundamentais. A instrução elementar será obrigatória. A instrução técnicoprofissional será acessível a todos, bem como a instrução superior, esta baseada no mérito. 
Art. XXVI - A instrução será orientada no sentido do pleno desenvolvimento da personalidade humana e do fortalecimento do respeito pelos direitos humanos e pelas liberdades fundamentais. A instrução promoverá a compreensão, a tolerância e a amizade entre todas as nações e grupos raciais ou religiosos, e coadjuvará as atividades das Nações Unidas em prol da manutenção da paz.

Por essa concepção exposta acima, vê-se que o comportamento da sociedade reflete-se na escola. Quanto aos educadores, o atendimento a seus direitos humanos de boa formação acadêmica, as condições de trabalho adequadas, o reconhecimento de sua importância social e políticas públicas compatíveis facilitam práticas educativas que respeitam os direitos humanos dos cidadãos em formação, que são os alunos, e também a comunidade. Por isso, não podemos ficar de braços cruzados, simplesmente, aguardando uma atuação dos nossos líderes políticos, que nos representam democraticamente. Tem-se que partir de uma reação de cada indivíduo.

\section{Democracia e as garantias constitucionais para assegurar os direitos sociais: educação}

Hodiernamente, o que se detecta é que a escola está sendo desafiada a construir nova ponte: a ponte que promove a integração social pelo desenvolvimento da cultura centrada no respeito e na vivência dos direitos humanos. O que se percebe, no entanto, é que o Estado terá o dever de promover os direitos humanos de segunda dimensão, caracterizando a prestação positiva por meio de política pública, que visa a garantir às pessoas a satisfação de suas necessidades mais básicas, especialmente, a educação.

De outro lado, destaca-se o papel da família, que também terá o dever de buscar a instrução para seus membros, promovendo o incentivo e os meios adequados para que a criança tenha possibilidade de frequentar a escola. Ainda, ressaltamos que os profissionais de educação terão que se qualificar para melhorar a qualidade do ensino, por meio de ações, programas democráticos, cursos de especializações, isso para que se tenha uma visão geral de organização do trabalho, do desenvolvimento da função do gestor e do supervisor que estejam sempre em sintonia com a equipe da escolar. Assim buscando sempre a atualização, visando 
ao pleno desenvolvimento da pessoa, haverá preparo para o exercício da cidadania e a qualificação para o trabalho. $\mathrm{O}$ acesso à escola pública é instrumento de democratização, sem o que não se pode falar em atendimento a direitos humanos, porém, é apenas o primeiro passo. Para o seu atendimento, não é suficiente debater temas relacionados aos direitos humanos. Nenhum conteúdo é suficiente para formar valores e atitudes comprometidas com ética e moral. Para uma educação em direitos humanos, os conteúdos precisam ser complementados com o cultivo de valores e atitudes, como expõe Gimeno Sacristan:

O direito a receber educação, o acolher os direitos humanos na educação como conteúdos do currículo (constituindo uma matéria, sendo objeto de ensino dividido entre várias delas ou sendo objetivos comuns a todo o ensino) e o desenvolver a educação conforme os direitos humanos são referências complementares e interdependentes para conceber a educação e realizá-la com uma visão universal e moral (GIMENO SACRISTAN, 2007).

É uma concepção de democracia que pode realizar, no campo da educação, ações que efetivamente constróem-se com a participação dos sujeitos sociais, no seu pleno sentido, defendido por Benevides:

Democracia é o regime político da soberania popular, porém com respeito integral aos direitos humanos. A fonte do poder está no povo que é radicalmente o titular da soberania e que deve exercêla - seja através de seus representantes, seja através de formas diretas de participação nos processos decisórios. É o regime de separação de poderes e, essencialmente, é o regime da defesa e da promoção dos direitos humanos. E quando me refiro à garantia dos direitos humanos, estou unindo a democracia política e a democracia social. A democracia política, herdeira do liberalismo, com as liberdades individuais e as liberdades públicas, que são o fundamento dos direitos civis elementares. A democracia social, fruto de lutas sociais e da consolidação dos valores da igualdade e da solidariedade, acrescidos ao valor da liberdade. (BENEVIDES, 2002).

Quando a democracia é compreendida como socialização crescente da política rumo à socialização do poder, como conquista efetiva de regras do jogo que mudam se aprofundam e se transformam, 
e também de igualdade substantiva, é possível afirmar com clareza, que o modelo político, econômico e social que foi implantado no país, na última década, é incompatível com essa concepção de democracia.

Quando compreender o pensamento de Bobbio (2000) de "democracia, entendida como contraproposta a todas as formas de governo autocrático", certamente poderá assumir a atitude democrática na gestão escolar.

No que diz respeito às modalidades de decisão, a regra fundamental da democracia é a regra da maioria, ou seja, a regra na qual são consideradas decisões coletivas - e, portanto, vinculatórias para todo o grupo - as decisões aprovadas ao menos pela maioria daqueles a quem compete tomar a decisão. (BOBBIO, 2000).

No Brasil, a Constituição de 1988 representa a consagração do Estado Democrático de Direito. O Artigo 208, Inciso I, considera a educação básica dos 4 aos 17 anos de idade, obrigatória, assegurada, inclusive, sua oferta gratuita para todos os que a ela não tiveram acesso na idade própria (Emenda Constitucional no 59, de 11/11/2009) é um direito subjetivo de todo brasileiro ( Inc.VII, $\int 1^{\circ}$ ), reafirmado pela Lei de Diretrizes e Bases da Educação Nacional 9394/965. No entanto, entre a lei e seu cumprimento, a distância é grande e nem sempre se encontram. Vive-se no Estado o paradoxo ${ }^{6}$ de direitos incisivamente proclamados, mas nem sempre há efetividade.

A década de 1990 foi marcada por movimentos importantes; assim destacamos o $1^{\circ}$ Congresso Brasileiro de Educação em Direitos Humanos e Cidadania, em 1997, a elaboração de documentos sistematizadores de conceitos e fundamentação histórica e teórica e referencial metodológico sobre o tema educação e direitos humanos, a elaboração do Programa Nacional de Educação em Direitos Humanos que, entre outras propostas, aponta para a necessidade de criar e fortalecer na escola o respeito aos direitos humanos.

Nesse sentido, os Parâmetros Curriculares Nacionais para o Ensino Fundamental, propõem os temas transversais em estruturação, organização e desenvolvimento curricular. A lei federal 9394/96 também assinala indicadores importantes dos direitos humanos, reafirmando o princípio da base nacional comum a ser complementada por uma parte diversificada e assegura também a possibilidade de a escola organizar-se por ciclos.

Enquanto experiências decorrentes desses movimentos, podese tomar como exemplo a Escola cidadã (secretaria Municipal de Porto
5. Lei de Diretrizes e Bases da Educação Brasileira (LDB 9394/96) é a legislação que regulamenta o sistema educacional (público ou privado) do Brasil (da educação básica ao ensino superior).

6. Caracteriza-se, assim, o que foi chamado de paradoxo da teoria de Bourdieu: a cultura ora atuando como mecanismo de reprodução das condições sociais, ora como um veículo de mudança social. 
7. Para Bourdieu campo é uma rede, ou configuração, de relações objetivas entre posições. Essas posições são objetivamente definidas, em sua existência e nas determinações que impõem sobre os ocupantes, agentes ou instituições, pela sua situação presente e potencial na estrutura de distribuição de espécies de poder (ou capital), cuja posse comanda o acesso aos lucros específicos que estão em jogo no campo, assim como pelas suas relações objetivas com outras posições (dominação, subordinação, homologia). (BOURDIEU, 1989, p. 64-65).

8. Gestão Escolar é relativamente recente e de extrema importância, na medida em que desejamos uma escola que atenda às atuais exigências da vida social: formar cidadãos críticos, oferecendo, ainda, a possibilidade de apreensão de competências e habilidades necessárias e facilitadoras da inserção social. Isto permite pensar gestão no sentido de uma articulação consciente entre ações que se realizam no cotidiano da instituição escolar e o seu significado político e social. (Nelson, 2010, p.3).
Alegre- RS), pois, esse projeto compõe um conjunto de mecanismos, visando a constituir a forma pela qual o saber pedagógico pode ser ampliado, assim delineando um campo de possibilidades para ativar o processo de ensino. Essa proposta responde às questões centrais do campo da educação ${ }^{7}$, no que se refere ao conteúdo a ser ensinado, à forma como isso deve ser realizado e ao tipo de cidadão que se pretende construir. E, dessa maneira, a Escola Cidadã estabelece e dá visibilidade à verdade pedagógica do momento presente, assim articulando sob a tríade poder-conhecimento-cidadania.

Dessa forma, a sociedade deve manter compromisso mais forte e delineador, quando se trata de educação para a busca da cidadania democrática. Deve lembrar que a educação está inserida no texto constitucional, contemplando os direitos sociais mais amplos como a educação, designados também, como segunda dimensão de direitos humanos, que são fundamentais à contemplação do princípio matriz do ordenamento jurídico constitucional, que é a dignidade da pessoa humana.

\section{Gestão Escolar como paradigma para a organização e o desenvolvimento do sistema Escolar}

No Brasil há muita variação e, em alguns lugares, há carência de recursos escolares, infraestrutura, material didático, capacitação dos docentes e a existência desses recursos podem fazer a diferença em organização e gestão da escola. Dessa forma, cabe à gestão escolar implantar soluções estratégicas que vise à eficácia escolar ${ }^{8}$, no que tange à liderança, à responsabilidade que prioriza o ensino e a aprendizagem dentro e fora da escola, com resultados positivos para toda a sociedade e seus desafios.

A gestão escolar busca a eficiência, por meio de sua organização pedagógica escolar, sempre visando a uma missão clara centrada no aprendizado de conhecimento e valores a todos os alunos, um projeto pedagógico elaborado, com vistas às necessidades do local, buscando ser compartilhado por toda a comunidade. Numa escola eficaz, o plano pedagógico e suas estratégias são atingidos com sucesso, podendo fazer da escola um ambiente agradável, construtivo e, ainda, envolvendo a participação de toda a comunidade. Esses fatores, quando bem 
estruturados, estimulam a aprendizagem e a sociedade juntamente com a escola e trabalham para a formação da cidadania de forma respeitosa, colaborativa e com o fim social do alcance da dignidade e dos valores éticos.

A gestão democrática implica a efetivação de novos processos de organização e gestão baseados, numa dinâmica que favoreça os processos coletivos e participativos de decisão (BRASIL, 2005).

Para que a participação seja realidade, são necessários meios e condições favoráveis, ou seja, é preciso repensar a cultura escolar e os processos, normalmente autoritários, de distribuição do poder no seu interior (...) Outro dado importante é entender a participação como processo a ser construído coletivamente. Nessa direção, é fundamental ressaltar que a participação não se decreta, não se impõe e, portanto, não pode ser entendida apenas como mecanismo formal/legal (BRASIL,2005).

Por outro lado, a gestão escolar é uma inovação de administração e coordenação do sistema escolar que pugna pelo desenvolvimento da escola, e envolve competência técnica, no desenvolvimento da gestão pedagógica, e uma liderança junto à equipe escolar e na comunidade visando a estimular a participação dos pais e familiares. Para fim de melhor entendimento, costuma-se classificar a Gestão Escolar em três módulos distintos e interligados, no funcionamento estrutural e na liderança do diretor da escola.

Primeiro módulo da gestão escolar é a gestão pedagógica que trata de estabelecer os objetivos para o ensino, definindo as linhas de atuação, em função dos objetivos e do perfil da comunidade e dos alunos. Elabora os conteúdos curriculares. Acompanha e avalia o rendimento das propostas pedagógicas, dos objetivos, e o cumprimento de metas. Avalia o desempenho dos alunos, do corpo docente e da equipe escolar como um todo. As especificidades são enunciadas no Regimento Escolar e no Projeto Pedagógico da escola. O Diretor é auxiliado pelo Coordenador Pedagógico. Também faz em parte da proposta pedagógica: a avaliação e o treinamento da equipe escolar.

O segundo módulo é a gestão administrativa que cuida da parte estrutural, física e da parte institucional que se inclui legislação escolar, direitos e deveres, atividades de secretaria. Suas especificidades estão enunciadas no Plano Escolar. 
E o terceiro módulo é a gestão de Recursos Humanos que, sem dúvida, requer atuação ativa do diretor que busca estimular os profissionais da educação, mantendo-os trabalhando com perspectivas de melhorias do rendimento escolar, ou seja, mudanças de fundo nos processos de ensino e nas estratégias centrais de mudanças. Por outro ângulo, a gestão de recursos humanos procura dimensionar o relacionamento humano em equilíbrio nos termos de fracasso ou sucesso de toda formulação educacional a que se pretenda dar consecução na escola.

O modelo explicitado acima corresponde a uma construção teórica e prática da realidade escolar. Os três módulos não podem ser separados, pois devem desenvolver-se de forma interligados, visando a garantir a organicidade do sistema educacional. Dessa maneira, é possível visualizar a importância da gestão escolar, quando se fala em mediação entre equipe escolar e seu desenvolvimento compartilhado junto da comunidade.

Com isso, verifica-se que há um vácuo na visão panorâmica e global da escola como instituição social e de ensino; falta percepção entre os elementos que vinculam as articulações educativas e as políticas públicas de educação. Os procedimentos pedagógicos que visam à promoção as melhores instituições educacionais estão carentes deles. Essa sintonia seria promovida, estimulada e orientada sob a liderança do diretor do estabelecimento de ensino, juntamente com sua equipe gestora, voltada para a dinamização e a coordenação no processo participativo para atender a escola, as demandas educacionais da sociedade dinâmica, centrada em tecnologia e conhecimentos.

9. A mediação é democrática porque estimula a participação ativa das pessoas na solução de conflitos e propicia a inclusão social quando deixa que elas busquem por elas mesmas a solução de seus problemas. SALES, Lilia Maia de Morais. Justiça e mediação de conflitos. Belo Horizonte: Del Rey, 2004.

\section{A gestão educacional como mediadora na educação em uma comunidade}

O reconhecimento e a efetivação do papel desempenhado pela gestão educacional funcionam como mediação ${ }^{9}$, frente aos problemas educacionais e à realidade social de uma comunidade. O gestor educacional atua como articulador do trabalho coletivo da escola, sendo aquele que articula a concepção de educação da escola com as relações e determinações políticas, sociais, culturais e históricas.

Por outro lado, a gestão educacional terá que ser mediadora para subsidiar teoria e aplicação do método, com as formas de condução do conhecimento e a prática docente. A escola, como instrumento 
de divulgação do saber e principal formadora da cidadania, possui a responsabilidade de transformar o conhecimento difuso em sistematizado, por meio do processo de ensino e aprendizagem. Assim, Coutinho afirma quando diz que:

a gestão democrática da educação compreende noção de cidadania como capacidade conquistada por todos os indivíduos, de se apropriarem dos bens socialmente criados, de atualizarem todas as potencialidades de realização humana abertas pela via social em cada contexto histórico determinado (COUTINHO, 2000)".

Entendemos o conceito de mediação na aprendizagem tendo como referência a perspectiva de interação social de Vygotsky (1989; 1998). Segundo essa abordagem, a atividade mediada é o meio para o desenvolvimento e o acesso aos objetos de conhecimento como decorre da afirmação de que "[a] transmissão racional e intencional da experiência e pensamento a outros requer um sistema mediador..." (Vygotsky, 1998).

Dessa forma, considera-se que a comunidade é um sistema plural e um coletivo de conhecimento; a interação entre os membros é constituída por múltiplos discursos através dos quais se realiza a negociação do sentido das aprendizagens do grupo.

$O$ processo de exposição às diferentes perspectivas implica, por sua vez, o desenvolvimento de um ambiente de confiança mútua promovido pelo mediador. Sob esse ângulo, Adorno afirma:

que temos que pensar a sociedade e a educação em suas mudanças constantes e sua perenidade, assim poderíamos nos ater a história para que todos reflitam sobre os acontecimentos de barbárie, estando aptos a mudar o seu rumo de forma positiva. (ADORNO, 1995).

Construir cidadãos éticos, ativos, participativos, com responsabilidade diante do outro e preocupados com o universal e não com particularismos, é retomar as utopias e priorizar a mobilização e a participação da comunidade educativa na construção de novas agendas. Essas agendas devem contemplar projetos emancipatórios que tenham como prioridade a mudança social, qualifique seu sentido e significado, pense alternativas para um novo modelo econômico não excludente que contemple valores de uma sociedade em que o ser humano é centro das 
atenções e não o lucro, o mercado, o status político e social, o poder em suma. A educação não-formal é um campo valioso na construção daquelas agendas, e para dar sentido e significado às próprias lutas no campo da educação, visando à transformação da realidade social.

Diante disso é importante distinguir que a sociedade é incoerente em certos momentos sendo ao mesmo tempo progressista e conservadora. Com todo o conhecimento e a técnica adquiridos, a sociedade já tem condições de extirpar a miséria da face da terra, mas devido a interesses políticos daqueles que dominam, essa ação continuará a ser negada. O pessimismo não deve prevalecer, mas é necessário agir dentro dos poderes estabelecidos para que se possa fortalecer a sociedade e a luta política. A classe dominante continua sendo privilegiada pelo progresso, a contradição está cada vez mais presente nos direitos proclamados pela sociedade: cada discurso ${ }^{10}$ sobre justiça se observa menos justiça, a liberdade camufla-se na opressão, e a felicidade só existe na ilusão do consumo. Somente políticas radicais conseguem manter o interesse da classe dominante, porque a ideologia liberal não é mais capaz de ocultar a exploração social.

Por outro lado, há necessidade de implantar uma proposta de caráter sociopolítico: a de transformar as escolas em centro de referências civilizatórias nos bairros onde se localizam. Para isso propõe-se uma articulação dos processos de participação da sociedade civil organizada com as escolas. Desse modo, busca-se a articulação da educação formal com a não-formal para dar vida e viabilizar mudanças significativas na educação e na sociedade como um todo. Com isso, a Pedagogia Social se legitimará como área fundamental no campo da produção de conhecimento.

Marx e Engels declaram: "Não é a consciência que determina a vida, mas a vida que determina a consciência" (MARX; ENGELS, 1976). Em outras palavras, não é a ideia que produz a vida, mas é a vida - existencialmaterial-concreta - que produz as ideias. Nesse sentido, o homem não

10. A produção do discurso é ao mesmo tempo controlada, organizada e redistribuída por certo número de procedimentos que têm por função conjurar seus poderes e perigos, dominar seu acontecimento aleatório, esquivar sua pesada e temivel materialidade" (Foucault 1996 pp. 8-9) se constrói em sua essência, de forma autônoma, mas recebe influências e se vincula às suas reais condições de produção de sua existência e às formas de cooperação, trocas e intercâmbios. E, assim, como sujeitos concretos, situados num tempo e num espaço, os homens "atuam $e$ produzem materialmente e, portanto, tal e como desenvolvem suas atividades sob determinados limites, pressupostos e condições materiais, independentemente de sua vontade". (MARX; ENGELS, 1976). 
A escola é um fórum de participação e existe para servir a comunidade. Para Luhmann (apud DUSSEL, 2002), "o sujeito autoconsciente está no entorno". Por isso, a comunidade tem de estar dentro da escola, participando, intervindo, direcionando seus rumos, de forma democrática e solidária. Para que isso ocorra de forma construtiva, é preciso que a comunidade, na interação com outros, na práxis de intervenção, passe pelo processo de autolibertação, conscientizando-se de sua condição de opressão para, a partir daí, ousar corajosamente, para construir uma nova realidade.

A escola, como toda organização social, legitima-se pelo exercício adequado de sua função. Jornais, revistas científicas e populares, o rádio e a televisão alardeiam a situação precária do ensino público, com o pressuposto de que a maioria dos alunos é oriunda das camadas populares, carentes de capital cultural. Desmotivadora, conservadora, alienada de sua própria finalidade, a escola acentua a diferença inicial da demanda e contribui para o fracasso escolar. (BOURDIEU, 1998).

$\mathrm{Na}$ democracia real, em que a comunidade participa, os participantes podem falar, argumentar, comunicar-se chegar a consensos, ter co-responsabilidade, consumir produtos materiais, ter desejo de bens comuns, ansiar por utopias, coordenar ações instrumentais ou estratégicas, "aparecer" no âmbito público da sociedade civil com um rosto semelhante que os diferencia dos outros. (DUSSEL, 2002)

Para se combater o neoliberalismo ${ }^{11}$, é necessário sair do imobilismo e combater a ignorância e a inércia historicamente produzida, pois a exclusão social é resultado da imbecilização e da submissão ao sistema imposto. Podemos ver a alienação como consequência do "poder invisível". Em consequência, vem a luta "contra o poder, luta para fazê-lo aparecer e feri-lo onde ele é mais invisível e mais insidioso" (FOUCAULT, 2007).

A relação de mediação no trabalho social já é complexa em si mesma, devido à complexidade do educar. Os efeitos dessa complexidade se mostram ainda mais graves quando se trata de práticas de mediação em projetos e movimentos sociais, que trabalham com crianças, jovens e adultos que vivem em precárias condições sociais em nosso país ou até mesmo em situação de risco. Abordar e se relacionar com os educandos em qualquer tipo de situação educativa, a partir dos modelos pedagógicos convencionais, tem produzido grandes dificuldades de aprendizagem e desenvolvimento nessa população. Mas a presença dos paradigmas
11. O Neoliberalismo pode ser definido como um conjunto de idéias políticas e econômicas capitalistas que defende a não participação do estado na economia. De acordo com esta doutrina, deve haver total liberdade de comércio (livre mercado), pois este principio garante o crescimento econômico e o desenvolvimento social de um país. FRIEDMAN, M. Capitalismo e Liberdade. $2^{\text {a }}$ Ed. São Paulo. Nova Cultural, 1985. 
pedagógicos conservadores ainda é forte, de forma secreta e sutil, em muitos mediadores que se propõem a um trabalho de autolibertação popular.

A crença iluminista de mudança do sujeito a partir de conceitos e ideias é problemática no campo educacional, pois simplifica o que é complexo. Os processos de transformação do ser humano são muito mais complexos e envolvem bem mais do que o campo cognitivo e intelectual. Uma parte do pensamento social mais engajado, e inclusive do ativismo social, que esteve durante os séculos XIX e XX fortemente ligados a duas ideias de base racionalista, é herança da concepção de sujeito do século XVIII. A primeira é a crença segundo a qual quanto mais informação e conhecimento, mais pensamento, e quanto mais pensamento, mais consciência sobre a realidade. Ou seja, o processo de superação da alienação política é processo prioritariamente cognitivo.

Essa ideia sustentou e sustenta ainda parte das propostas mais engajadas de formação para a cidadania na modernidade. A sua representação gráfica em nossa realidade poderia ser feita da seguinte forma:

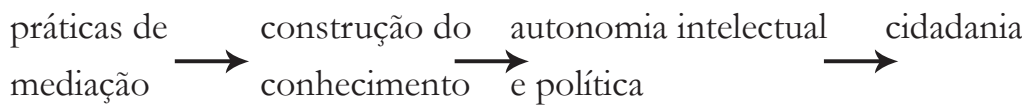

A mediação colaborativa constitui não só um processo de construção da interação social entre os membros da comunidade, mas também a forma de realização da liderança partilhada dos processos de interação no domínio da elaboração das aprendizagens no âmbito da rede. Entendemos, nessa perspectiva, que a mediação colaborativa, sustentada na liderança partilhada, constitui um meio facilitador para o acesso e a produção dos objetos e dos contextos de aprendizagem, e os sistemas de representação do conhecimento coletivo da comunidade.

Segundo Adorno, a dissolução da formação como conhecimento formativo é o motivo desse império que se encontra constituído, na dominação do existente; sendo assim, a autonomia dos homens, está subordinada à produção e à reprodução da vida humana em sociedade. $\mathrm{O}$ poder das relações sociais não afeta somente as condições da produção econômica e material, mas também nas relações de dominação sobre o individuo. (ADORNO, 1995) 
Assim, Adorno fornece grande importância ao que ele denominou “educação após Auschwitz", ${ }^{12}$ que teria, segundo ele, dois aspectos. Um seria a educação durante a primeira infância e o outro ao processo de esclarecimento da população, que seria um processo abrangente e geral que criaria um clima cultural e social que seria obstáculo para a repetição da barbárie. É neste contexto que Adorno critica a tese que aponta para a necessidade de "recuperar a autoridade" ou a realização de um "compromisso", e nem se trata, também, de se limitar ao caso alemão, que pode até contribuir para a explicação do fenômeno nazista naquela época, mas não tem papel relevante para evitar o retorno da barbárie. Ao evitar essas "soluções" Adorno revela sua posição:

O que a psicologia profunda denomina superego, a consciência moral,ésubstituída nocontextodos compromissos porautoridades exteriores, sem compromisso, intercambiáveis, como foi possível observar com muita nitidez também na Alemanha depois da queda do Terceiro Reich. Porém, justamente a disponibilidade em ficar do lado do poder, tomando exteriormente como norma curvar-se ao que é mais forte, constitui aquela índole dos algozes que nunca mais deve ressurgir. Por isto a recomendação dos compromissos é tão fatal. As pessoas que os assumem mais ou menos livremente são colocadas numa espécie de permanente estado de exceção de comando. O único poder efetivo contra o princípio de Auschwitz seria a autonomia, para usar expressão kantiana; o poder para a reflexão, a autodeterminação, a nãoparticipação. (Adorno, 1995).

Se não há a integração total da sociedade, devido à própria contradição social, que funciona como o antídoto da semiformação, então continua existindo a possibilidade de emancipação. Essa questão foi abordada por Adorno, no último ensaio do livro Educação e Emancipação: “... é preciso comę̧ar a ver efetivamente as enormes dificuldades que se opõem à emancipação nesta organização do mundo (...). O motivo é a contradição social' (ADORNO, 1995a).

Por esse lado é possível vislumbrar o alcance e a dimensão das novas tendências educacionais, mediante as ações da gestão educacional que visam à inovação e devem ter como fundamento subsidiar as mudanças da sociedade, ainda que de forma indireta, pois a escola, como toda instituição, acompanha as modificações sociais.
12. 0 ocorrido de Auschwitz foi um dos fatos mais marcantes na história da humanidade. Theodor W. Adorno aborda uma questão essencial para entender o passado cíclico-histórico referente ao Holocausto na Alemanha Nazista. Em "Educação após Auschwitz", sugere que as condições sociais objetivas que jogaram a humanidade à barbárie já são a barbárie. A "educação contra a barbárie" exige uma crítica radical dessas mediações objetivas e subjetivas pressupostas, que segundo nossa compreensão, aponta para o caráter fetichista da sociedade da mercadoria baseada no trabalho abstrato. Que é muito concreto. Adorno não quer que isso seja esquecido pela humanidade e muito menos repita. ADORNO, T. Educação e Emancipação. Rio de Janeiro: Paz e Terra, 1995. 


\section{Considerações Finais}

A sociedade contemporânea defronta-se com a diversidade de acontecimentos como a intolerância cultural e racial e situações de desigualdades e injustiças sociais, cada vez mais crescentes, isto naturalmente, provenientes das contradições do capitalismo e do processo de transformação do mundo globalizante, que demarcam a existência de uma crise, ou seja, de um desarranjo paradigmático no campo da ciência, o qual interfere na política, na cultura e principalmente, na educação e nas praticas sociais.

Dessa forma possibilita-se a visão de que estamos saindo do século das certezas e entrando no século das dúvidas, construindo-se o cidadão e sua formação ética, uma das questões fundamentais do debate no contexto da pós-modernidade.

Os direitos humanos buscam a máxima efetividade do princípio da dignidade humana, com vistas a sua amplitude e luta pela formação de uma cidadania integradora, que visa a um desenvolvimento social, para redução de desigualdades e injustiças sociais, isto por meio da elevação do nível educacional em todos os meios da sociedade.

A gestão educacional é um instrumento mediador, que tem potencial para difundir o caráter transformador que a educação possui diante de qualquer sociedade. A postura do educador em construir métodos pedagógicos é essencial para a universalização do acesso à escola e à melhora do ensino-aprendizagem, com intuito de uma construção digna, ampla, de nível educacional mais elevado e que tenha resultados positivos.

A educação em direitos humanos requer forma compartilhada de visualização das necessidades que permeiam a comunidade. Assim possibilitam oportunidade para a comunidade manter aproximação com a escola e com os problemas vivenciados por ambas; isso para que haja junção dos interesses que serão discutidos em conjunto. Dessa maneira, podem os desafios da realidade social ser minimizados e poderão ainda propor ações de complementação educacional que contribuam para a formação de uma sociedade norteadora por uma nova tendência - a cultura e a disseminação dos direitos humanos.

Por outro lado, salienta-se que o trabalho desenvolvido pela gestão educacional, muitas vezes, assume uma vertente direcionada dentro do espaço escolar, limitando a condição gerencial-operacioal, isso somente 
no âmbito das políticas públicas, decorrentes de determinações de natureza administrativa definidas pelo MEC.

Ainda, sob o enfoque de a gestão educacional ser mediadora entre escola e comunidade, essa ideia transposta para o processo de ensinoaprendizagem, considerando que a grande tarefa da educação é preparar o ser humano para solucionar e buscar meios de resolução dos problemas e/ou desafios que surgirão durante a sua vida do cidadão.

Acreditamos que o neoliberalismo visualiza a educação de forma específica, apontando algumas objeções centrais no campo educação, que devem ser operacionalizadas pelo gestor educacional, assim expondo qualidade total, modernização da escola, adequação do ensino à competitividade do mercado internacional, nova vocacionalização, incorporação de técnicas e linguagens da informática e da comunicação, abertura da universidade aos financiamentos empresariais, pesquisas práticas, utilitárias, produtividade. Isso deve ser configurado como atuação atuando geral e estruturante na mediação das práticas pedagógicas e no contexto social.

É importante que a sociedade, na vertente neoliberal, seja consciente e não leve a educação como problema de articulação política, pois a educação terá que ser amparada pelo Estado, pela sociedade e por dirigentes como instrumento primordial capaz de transformar a sociedade e solucionar suas desigualdades e seus desafios sociais. Sob esse aspecto, muitas vezes, alguns dos problemas econômicos, sociais, culturais e políticos abordados pela educação são transformados em problemas administrativos e técnicos. Esse fato ocorre quando a escola não possui boa gestão educacional, não tenha visão de mediação entre a comunidade e as práticas pedagógicas para a solução de conflitos.

\section{Referências}

ADORNO, T. Educação e Emancipação. Rio de Janeiro: Paz e Terra, 1995.

ALVES, J. A. L. A arquitetura internacional dos direitos humanos. São Paulo: FTD, 1997.

APPLE, M. e BEANE, J. (orgs.). Escolas Democráticas. São Paulo: Cortez, 2001. 
BENEVIDES, Maria Victoria. A construção da democracia no Brasil pós-ditadura militar. In: FÁVERO, Osmar e SEMERARO, Giovanni (orgs.) Democracia e construção do público no pensamento brasileiro. Petrópolis: Vozes, 2002.

BOBBIO, Norberto. O futuro da democracia. 7. ed. São Paulo: Paz e Terra, 2000.

A Era dos Direitos. Tradução de Carlos Nelson Coutinho. Nova edição. Rio de Janeiro: CAMPUS, 2004.

BOURDIEU, P. $A$ Escola conservadora: as desigualdades frente à escola e à cultura. IN:

NOGUEIRA, M. A. e CATANI, A. (orgs.). Escritos de Educação. Petrópolis: Vozes, 2001.

. Escritos de educação. Rio de Janeiro: Vozes, 1998.

.O Poder Simbólico. Lisboa: Difel; Rio de Janeiro: Bertrand Brasil, 1989.

BRASIL. Constituição da República Federativa do Brasil de 1988. Diário Oficial da União no 119-A. Brasília, 5 de outubro de 1988. . Lei $\mathrm{n}^{\circ}$ 9394, de 20 de dezembro de 1996. Estabelece as diretrizes e bases da educação nacional. Diário Oficial da União, Brasília, 20 dez. 1996.

.Lei $\mathrm{n}^{\circ} \mathbf{8 0 6 9}$, de 13 de julho de 1990 . Dispõe sobre a proteção integral à criança e ao adolescente. Diário Oficial da União, Brasilia, 13 jul. 1990.

. Plano Nacional de Educação em Direitos Humanos, de 10 de dezembro de 2006. Comitê Nacional de Educação em Direitos Humanos. Brasília: Secretaria Especial de Direitos Humanos, 2006.

. Secretaria Especial dos Direito Humanos. Programa Nacional de Direitos Humanos (PNDH-3). Brasília: SEDH/PR, 2010.

. Conselho Escolar, gestão democrática da educação e escolha do diretor. Brasília/DF. v. 5, 2005.

CONNELL, R. W. Pobreza e Educação. In: GENTILI, P. (org.) Pedagogia da Exclusão. Petrópolis: Vozes, 1995.

CONTEÚDO aberto. In: Wikipédia: a enciclopédia livre. Disponível em: http: / / a-enciclopedia-livre.info/?title=Consenso. Acesso em: 8 jult 2013. 
COUTINHO, C. N. Contra a corrente: ensaios sobre a democracia e o socialismo. São Paulo: Cortez, 2000.

DUARTE, C. S. Direito público subjetivo e políticas educacionais. São Paulo em perspectiva. São Paulo, v. 18, n. 2, 2004.

DUSSEL, E. Ética da libertação: na idade da globalização e da exclusão. Tradução Ephaim Ferreira Alves, Jaime A. Clasen, Lúcia M. E. Orth. 2. ed. Petrópolis, R.J.: Vozes, 2002.

FÁVERO, Osmar; SEMERARO, Giovanni (orgs). Democracia e construção do público no pensamento brasileiro. Petrópolis Vozes, 2002.

FOUCAULT, M. A ordem do discurso. 2 ed., São Paulo: Edições Loyola,1996.

. Microfísica do poder. 23. ed. Tradução Roberto Machado.

Rio de Janeiro: Graal, 2007.

FRIEDMAN, M. Capitalismo e Liberdade. $2^{\mathrm{a}}$ Ed. São Paulo. Nova Cultural, 1985.

GIMENO SACRISTÁN, J. A Educação que ainda é possível. Ensaios sobre uma cultura para a educação. Porto Alegre: ARTMED, 2007.

MARX, K.; ENGELS, F. A ideologia alemã. Lisboa: Presença, 1976. $2 \mathrm{v}$.

MUNIZ, R. M. F. O direito à educação. Rio de Janeiro: Renovar, 2002.

NELSON, Ionara Bezerra. A gestão educacional e suas implicações para a organização e o desenvolvimento do trabalho escolar. http://www.ufpi.br/subsiteFiles/ppged/arquivos/files / VI.encontro.2010/GT.5/GT_05_04_2010.pdf. Acesso em: 21 de ago. 2013.

ORGANIZAÇÃO DAS NAÇÕES UNIDAS (ONU). Resolução 217. A de 10 de dezembro de 1948. Declaração Universal dos Direitos Humanos. Site: www.dhnet.org.br/direitos/deconu/textos/ integra/htm.

SALES, Lilia Maia de Morais. Justiça e mediação de conflitos. Belo Horizonte: Del Rey, 2004.

VIGOTSKY, L.S., Pensamento e Linguagem. São Paulo: Martins Fontes, 1989. 
. Psicologia da Arte. São Paulo: Martins Fontes, 1998.

WEYH, Cênio Back; DUARTE, Letícia Rieger. SILVA, Mariana Scholze da. Participação e diálogo no caminho da educação popular. Vivências. Vol.6, N.11: p.107-111, Outubro/2010.

Maria Gorete Ferreira é mestranda pelo Programa de Pós-graduação Stricto Sensu em Direito da Faculdade de Direito do Sul de Minas.

http:/ lattes.cnpq.br/1757644387080248

mgfunivas@hotmail.com

Rosa Maria do Nascimento é Professora titular da Universidade do Vale do Sapucaí e mestre em Enfermagem pela Universidade Federal de Minas Gerais.

http:/ / lattes.cnpq.br/8132216003776680

pesquisa@univas.edu.br 